\title{
JUAN EDUARDO CIRLOT, HISTORIADOR DEL ARTE
}

\author{
JUAN EDUARDO CIRLOT, ART HISTORIAN
}

\author{
Rafael Cómez Ramos \\ Universidad de Sevilla. España \\ rcomez@us.es
}

La celebración del ciento aniversario del nacimiento del poeta, compositor y crítico Juan Eduardo Cirlot nos invita a considerar su actividad como historiador del arte, aspecto con frecuencia olvidado de su vida y obra.

Palabras claves: Juan Eduardo Cirlot; crítica de arte; historia de la crítica de arte en España; arte contemporáneo en España; historiadores del arte críticos.

The celebration of the hundredth anniversary or the birth of the poet, composer and critic Juan Eduardo Cirlot invites us to reconsider his life and work as an historian of art. The purpose of this paper is to discuss this argument often neglected.

Keywords: Juan Eduardo Cirlot; art criticism; history of art criticism in Spain; contemporary art in Spain; critical historians of art.

La efemérides con ocasión del centenario del nacimiento del polifacético y fecundo escritor catalán Juan Eduardo Cirlot dará lugar a muchos comentarios y valoraciones de su obra además del completo estudio biográfico y crítico de Antonio Rivero Taravillo ${ }^{1}$. Sin embargo, aquí y ahora deseamos destacar su labor no solo como crítico de arte sino también como historiador del arte, la cual suele pasar desenfocada entre su prolífica producción como crítico de arte. Salvo un párrafo de Juan Antonio Gaya Nuño en su Historia de la crítica de arte en España de 1975, dos años después de su muerte, sobre la "muy compleja" personalidad de Cirlot $^{2}$, nada encontramos sobre nuestro autor hasta 1992 cuando

${ }^{1}$ RIVERO TARAVILLO, Antonio: Cirlot, ser y no ser de un poeta único. Sevilla, 2016.

2 GAYA NUÑO, Juan Antonio: Historia de la crítica de arte en España. Madrid, 1975, p. 321. El mismo autor lo incluye en la bibliografía general aunque no lo menciona 
merece la consideración de Valeriano Bozal al referirse a los escasos estudios sobre arte español contemporáneo en la primera mitad de los años sesenta del siglo XX, dentro de su introducción general al panorama de la pintura y escultura españolas del siglo XX, recordando la importancia de críticos como José María Moreno Galván, Vicente Aguilera Cerni y Juan Eduardo Cirlot con sus "casi siempre deslumbrantes"3 monografías. Cuatro años después vendría su resurrección gracias a la muestra del IVAM valenciano, comisariada por Enrique Granell y Emmanuel Guigon, que ponía ante nuestros ojos manuscritos, textos, partituras, revistas, que nos hablaban del hombre raro y único que fue Cirlot, y en cuyo catálogo figuraban preciosos textos de Juan Perucho, Rafael Santos Torroella, Antonio Saura y Carlos Edmundo de Ory ${ }^{4}$, explicando la obra de este poeta que entendía el arte.

Así pues, trataremos en primer lugar sobre la proteica personalidad del extraordinario personaje: poeta, músico, crítico de arte y tratadista de simbología, para pasar después, en segundo lugar, a comentar su figura como historiador del arte.

Independientemente de su cualidad creadora que le hizo destacar en distintos géneros pues era poeta, en primera instancia, y poeta es el que crea, su valor como crítico quedó plasmado no solo en sus monografías sobre Gaudí, Miró y Tapies sino también en sus libros sobre el surrealismo, la pintura abstracta, el arte del siglo XX o su tratado sobre los ismos en forma de diccionario. Ahora bien, aquí debemos plantearnos la cuestión que en aquellos años y también mucho después primó en los ambientes intelectuales y universitarios españoles cuando se hacía una tajante separación entre los críticos y los historiadores del arte de tal modo que los primeros serían aquellos que sin pertenecer a la Universidad practicaban la crítica de arte con sus publicaciones periódicas en diarios y revistas mientras que, por otra parte, los segundos eran los catedráticos universitarios que investigaban sobre el arte y en raras ocasiones practicaban la crítica de arte en periódicos o revistas.

El grave error de esa escisión entre la historia del arte y la crítica del arte permaneció vigente en algunos departamentos universitarios españoles como puede

en el texto, $c f$. GAYA NUÑO, Juan Antonio: Arte del siglo XX, en Ars Hispaniae. Vol. XXII. Madrid, 1977.

${ }^{3}$ BOZAL, Valeriano: Pintura y escultura españolas del siglo XX (1900-1939), en Summa Artis. Historia general del arte. Vol. XXXVI. Madrid, 2000, p. 9.

${ }^{4}$ GRANELL, Enric y GUIGON, Emmanuel (com.): Catálogo de la exposición Mundo de Juan Eduardo Cirlot. Valencia, 1996. La última exposición ha sido la organizada también por GRANELL, Enric: La habitación imaginarialJuan Eduardo Cirlot. Barcelona, 2011. 
comprobarse no solo en la larga nómina de profesores universitarios mencionados por Gaya Nuño donde figura únicamente la personalidad señera de Julián Gállego "como crítico de arte actual" 5 , sino también en las páginas dedicadas por el inolvidable Lafuente Ferrari a la historia y la crítica ante la obra de arte ${ }^{6}$. En este sentido, cabe recordar también en qué manera este gran historiador de la pintura española, excluido de la docencia universitaria por razones ideológicas aunque invitado varias veces por universidades de Estados Unidos, expuso la situación de la historia del arte en las universidades españolas en comparación con las norteamericanas en su enjundiosa introducción a la primera edición española de los estudios de iconología de Panofsky ${ }^{7}$. En el caso de Julián Gállego, es bien sabido que a pesar de su reconocido prestigio internacional como crítico de arte, al no tener validez administrativa su tesis doctoral francesa dirigida por Francastel en la Universidad de la Sorbona, hubo de presentar otra tesis de muy diferente estilo en la Universidad de Zaragoza con objeto de poder integrarse en la universidad española ${ }^{8}$.

Cirlot no fue un universitario pero precisamente por ello pudo permitirse una cultura universal. No son pocos méritos hablar de Miró en los años de la posgue$\mathrm{rra}^{9}$, pertenecer al movimiento Dau al Set ${ }^{10}$, o haber descubierto a Tapies, valorándolo desde un principio en El arte otro $(1957)^{11}$ y hasta el final de su vida ${ }^{12}$. Sin embargo, Cirlot fue quien explicó también a un nivel general la significación del surrealismo ${ }^{13}$, el expresionismo y la abstracción ${ }^{14}$, el cubismo y la figuración ${ }^{15}$

${ }^{5}$ GAYA NUÑO, J. A.: Historia de la crítica de arte..., op. cit., pp. 243-250.

${ }^{6}$ LAFUENTE FERRARI, Enrique: La fundamentación y los problemas de la Historia del arte. Madrid, 1951, pp. 27-31.

7 LAFUENTE FERRARI, Enrique: "Prólogo", en PANOFSKY, Erwin: Estudios sobre Iconología. Madrid, 1972, p. XXV.

${ }^{8}$ BORRÁS GUALIS, Gonzalo M. y PACIOS LOZANO, Ana Reyes: Diccionario de historiadores españoles del arte. Madrid, 2006, pp. 148-150.

${ }^{9}$ CIRLOT, Juan Eduardo: Joan Miró. Barcelona, 1949.

${ }^{10}$ BOZAL, Valeriano: Pintura y escultura españolas del siglo XX (1939-1990), en Summa Artis. Historia general del arte. Vol. XXVII. Madrid, 1992, pp. 209-213.

${ }^{11}$ CIRLOT, Juan Eduardo: Tapies. Barcelona, 1960; y CIRLOT, Juan Eduardo: Significación de la pintura de Tapies. Barcelona, 1962.

${ }_{12}$ En 1973, tres meses antes de morir, publicó un artículo en La Vanguardia donde se preguntaba si se reconocía el genio de Tapies, respondiendo así: "No del todo, y es porque la obra de Tapies, que carece de la cerrada unidad de la de Miró y tampoco tiene la sintética variedad de la de Picasso, es menos accesible para los doctos y para los que la glosan y la alaban”. Apud RIVERO TARAVILLO, A.: Cirlot, ser y no ser..., op. cit., p. 69.

${ }_{13}$ CIRLOT, Juan Eduardo: Introducción al surrealismo. Madrid, 1953.

${ }^{14}$ CIRLOT, Juan Eduardo: Del expresionismo a la abstracción. Barcelona, 1955.

15 CIRLOT, Juan Eduardo: Cubismo y figuración. Barcelona, 1957. 
o, del mismo modo, el informalismo ${ }^{16}$ con un afán didáctico y educativo en un tiempo en el que el arte contemporáneo era soslayado o incluso, en algunos ambientes, mal visto. Defendía el arte abstracto porque estaba fuera de la realidad y de ese modo reafirmaba su espíritu rebelde y su carácter nihilista al que, por el contrario, contradictoriamente, tampoco se adscribía, en esencia. Cirlot era el crítico que entendía el arte universal desde lo actual y por esa razón no solo era partícipe del arte de Tapies sino también de la obra de Dubuffet, del expresionismo abstracto americano, de Pollock, De Koonig, etc. ${ }^{17}$ De hecho, su correspondencia con artistas como Canogar, Cuixart, Chillida, Fontana, Manzoni, Millares, Miró y Saura nos demuestra su constante relación con el arte vivo de su tiempo ${ }^{18}$.

Espíritu universal al que nada resulta ajeno, nuestro autor, que admira a Wagner, Debussy y Ravel, se rinde fascinado ante la audición de El pájaro de fuego de Igor Strawinsky en el Liceo de Barcelona, dedicándole más tarde otro de sus libros ${ }^{19}$. Sin embargo, como miembro del Círculo Manuel de Falla, fundado en Barcelona en 1947, participó activamente como compositor presentando sus propias creaciones musicales: Vals (1942), Himno para piano (1943), Preludio para cinco instrumentos de cuerda (1943), Suite atonal (1947), Un poema de Rilke (1948), Preludio para quinteto con doble violonchelo (1948), Concertino para cuarteto de cuerda (1950), que culminarán en su descubrimiento de Schönberg y el dodecafonismo, sobre cuya teoría publicará un artículo en La Vanguardia de Barcelona $^{20}$.

Este período prolífico en lo creador y pródigo de inquietudes artísticas que coincide con los años cuarenta de la posguerra, es cuando el gran crítico de arte Eugenio D'Ors, después de crear en Madrid la Academia Breve de Crítica de Arte en $1942^{21}$, funda en Villanueva y Geltrú la Academia del Faro de San Cristóbal en $1946^{22}$, adonde acudiría también Cirlot en pos de conocimiento. No obstante, el gran acontecimiento artístico de estos años será la fundación de la revista Dau al Set por el editor e impresor Juan José Tharrats que se publicará desde 1948 a $1956^{23}$, y en la que colaborará asiduamente nuestro personaje desde el año si-

${ }^{16}$ CIRLOT, Juan Eduardo: Informalismo. Barcelona, 1959.

17 BOZAL, Valeriano: Pintura y escultura españolas del siglo XX (1939-1990), op. cit., p. 342.

${ }^{18}$ CIRLOT, Lourdes (ed.): Juan Eduardo Cirlot: de la crítica a la filosofía del arte: correspondencia con Canogar, Cela, Cuixart, Chillida, Fontana, Manzoni, Millares, Miró, Oteiza, Puig y Saura. Barcelona, 1997.

${ }^{19}$ CIRLOT, Juan Eduardo: Igor Strawinsky. Barcelona, 1949.

${ }^{20}$ RIVERO TARAVILLO, A.: Cirlot, ser y no ser..., op. cit., pp. 70-71.

${ }^{21}$ D'ORS, Eugenio: "La Academia Breve de Crítica de Arte", en Mis Salones. Itinerario del arte moderno en España. $2^{\mathrm{a}}$ ed., Madrid, 1967, pp. 97-123.

${ }^{22}$ GAYA NUÑO, J. A.: Historia de la crítica de arte..., op. cit., pp. 267-269.

${ }^{23}$ Ibidem, p. 321. El número de febrero de 1951 de Dau al Set estará dedicado a Cirlot. 
guiente de su creación cuando publica su monografía sobre Miró ${ }^{24}$ y su famoso diccionario sobre los ismos ${ }^{25}$. Uno de los componentes del grupo, Joan Brossa, aun considerando cierto matiz reaccionario de la ideología de Cirlot, afirmaba lo siguiente:

"Yo admiraba a Cirlot como crítico. En un momento en que Franco había depurado el arte de vanguardia con los mismos prejuicios de Hitler, que lo consideraba un arte judaico y decadente, Cirlot era el único que hablaba de arte contemporáneo y tenía un nivel comparable por ejemplo a Sebastiá Gasch”26.

En estos años conoce a los pintores Rafael Zabaleta y Benjamín Palencia, y al arquitecto Mathias Goeritz, que terminará sus días en México. Mantiene correspondencia con André Breton, al que dedica el poema Lilith, ilustrado con dibujos de Tapies y de Cuixart. Con este último viajará a Paris en octubre de 1949, donde entrará en contacto con Breton y los surrealistas ${ }^{27}$, gozando de la contemplación del arte abstracto en sus visitas al Museo de Arte Moderno. Como crítico de arte se ocupará siempre de promocionar a sus amigos y compañeros de tal manera que, en reciprocidad, Dau al Set le dedicará el ejemplar de febrero de $1951^{28}$. De su admiración por el arte abstracto resulta elocuente y es un buen ejemplo la dedicatoria al maestro del expresionismo abstracto: "Para Georges Mathieu" en su libro El espiritu abstracto $^{29}$, donde trata las distintas manifestaciones de la abstracción desde el arte prehistórico hasta el gótico.

Cirlot entabla amistad con Saura y es considerado por los pintores como uno de los más serios críticos de arte, informado asiduamente de todos los eventos que acontecen en París y otros centros artísticos europeos, y colaborando en las revistas Art Actuel International, Quadrum de Bruselas, Spazio de Milán y en las germanas Die Kunst y Das Kunstwerk. Sin embargo, dentro de la febril actividad que lleva en estos años hemos de destacar también que el 17 de febrero de 1956 actúa como narrador en el estreno de la película Piedras vivas en el Palau de la Música a beneficio de las obras del templo de la Sagrada Familia. Este film estaba realizado por Francisco Catalá y Anastasio Calzada con texto de Cirlot, I Premio Internacional de Cinematografía de Aficionados ${ }^{30}$.

${ }^{24}$ Véase nota 9.
${ }^{25}$ CIRLOT, Juan Eduardo: Diccionario de los Ismos. Barcelona, 1949.
${ }^{26}$ Apud RIVERO TARAVILLO, A.: Cirlot, ser y no ser..., op. cit., p. 81 .
${ }^{27}$ Ibidem, pp. 86-88, 106 y 116. Años después le enviará a Breton un ejemplar dedicado de su Morfología y arte contemporáneo.

${ }^{28}$ Ibidem, p. 102.

${ }^{29}$ CIRLOT, Juan Eduardo: El espíritu abstracto. $4^{\mathrm{a}}$ ed., Barcelona, 1993, p. 4. Sobre Georges Mathieu véase READ, Herbert: Historia de la pintura moderna. $2^{\mathrm{a}}$ ed., Barcelona, 1988, p. 279; y DORFLES, Gillo: Últimas tendencias del arte de hoy. $5^{\mathrm{a}}$ ed., Barcelona, 1976, pp. 23-26.

${ }^{30}$ RIVERO TARAVILlO, A.: Cirlot, ser y no ser..., op. cit., pp. 97 y 120. 
No cabe la menor duda de que el pensador catalán Eugenio d' Ors ocupa un lugar eminente en la historia de la crítica de arte en España, siendo una de las luminarias de nuestra cultura a nivel internacional cuyas aportaciones trascendentales a la estética y a la historia del arte lo corroboran. No solo sus variadas y extensas recopilaciones de jugosa crítica de arte sino también su investigación cimera sobre el estilo barroco así como sus libros sobre Goya, Cézanne o Picasso significaron auténticas novedades en la historiografía artística por su creatividad, especialmente, estos dos últimos que no habían recibido aún la consideración de la crítica en nuestra patria ${ }^{31}$. En este sentido, Gaya Nuño lo valoraba poniéndolo al mismo nivel de Palomino en cuanto a su aportación a la literatura artística, dedicándole todo un capítulo en su historia de la crítica de arte. Y también Cirlot, quien lo considera un maestro al que admira por su variedad y cuyas polifacéticas características son asimismo semejantes a las suyas, perteneciendo a esa pequeña república de las letras que representa la Academia del Faro de San Cristóbal en Villanueva y Geltrú, de la cual es miembro ${ }^{32}$.

\section{II}

Cuenta Victoria Cirlot en el epílogo a la tercera edición del Diccionario de Símbolos que en la correspondencia de su padre con el crítico de arte Herbert Read -quien prologaría en 1962 la traducción inglesa de este diccionario-, este se empeñaba en llamarle Professor Cirlot, a lo que contestaba el poeta que no era, ni había sido ni sería nunca profesor, por lo que apareció finalmente como Sr. Cir$\operatorname{lot}^{33}$. No lo era pero podía haberlo sido por su sabiduría en cualquier otro país, sin embargo, nuestro autor era un gran autodidacta, razón por la que poseía tan amplios conocimientos propios de un moderno humanista. Aprendió la crítica de arte del maestro Eugenio D'Ors, el surrealismo de André Breton, la abstracción de Cuixart y Tapies, el arte medieval de José Gudiol. De tal manera que en comunicación epistolar con Antonio Saura en 1959 -en un momento en que el panorama oficial respecto al arte contemporáneo en España está más despejado- se lamenta de la marginación cainita, fruto de odios y envidias, que sufre por su "surrealismo" cuando podría dirigir una revista, un museo o tener sencillamente un humilde puesto de trabajo ${ }^{34}$.

No fue profesor, pero contribuyó como pocos a la formación de varias generaciones de universitarios no solo con sus numerosos libros, sino también con sus diversas traducciones del inglés y francés, tanto de obras indispensables para

${ }^{31}$ GAYA NUÑO, J. A.: Historia de la crítica de arte..., op. cit., pp. 253-272.

32 RIVERO TARAVILLO, A.: Cirlot, ser y no ser..., op. cit., pp. 147-148.

${ }_{33}$ CIRLOT, Victoria: "Epílogo", en CIRLOT, Juan Eduardo: Diccionario de Símbolos. $3^{\text {a }}$ ed. Madrid, 1998, p. 491.

${ }^{34}$ Apud RIVERO TARAVILlO, A.: Cirlot, ser y no ser..., op. cit., p. 132. 
el conocimiento de la historia de la arquitectura española de los siglos XVII y $\mathrm{XVIII}^{35}$, como de otras más generales de alta divulgación referidas al arte contemporáneo ${ }^{36}$.

Nos ocuparemos aquí de comentar algunas de sus obras que consideramos fundamentales para comprender su talento como historiador del arte que suele quedar velado por su faceta de crítico de arte que aparece siempre destacada, aunque entendemos que no cabe distinción alguna entre ambas esferas de la misma profesión. En primer lugar destaca un libro genial, desconocido de muchos historiadores del arte -quizá porque no existe ningún ejemplar en nuestras bibliotecas universitarias-, que en cualquier otro ámbito que no fuera el español habría merecido excelentes referencias laudatorias. Trátase de Morfología y arte contemporáneo, publicado en 1955 por Ediciones Omega en su colección Poliedro (Figura 1) y que dedica "A la memoria de Arnold Schoenberg (1874-1951), destructor y constructor de formas" ${ }^{\prime 37}$. Ya mencionábamos más arriba su descubrimiento de Schönberg y la música dodecafónica que quedará plasmado en un artículo periodístico de La Vanguardia ${ }^{38}$.

En esta ocasión, la dedicatoria no es gratuita ya que el famoso compositor es el máximo exponente de la música contemporánea y a ese espíritu de complejidad dentro de las artes visuales va dedicada esta prolija obra donde lo oscuro se hace claro y lo artístico se pone en relación con la naturaleza gracias a los avances técnicos del siglo XX por medio del telescopio, la fotografía aérea o el microscopio electrónico, de tal modo que se confrontan ámbitos tan distintos como los de la astronomía, la biología, la microbiología, la botánica, la arquitectura y la pintura. En este sentido se adelanta muchos años a Rudolf Arnheim, cuando el gran psicólogo alemán observa la riqueza de formas de la naturaleza que aprovechan los artistas abstractos en sus innovaciones creadoras, cuyos elementos se enriquecen continuamente en la interacción de fuerzas siempre renovada de la vida orgánica e inorgánica del mundo físico ${ }^{39}$. Esta obra pretende desde la investigación y la divulgación aproximarnos al inextricable mundo de una "ciencia general de las formas" dentro de lo arriesgado del propósito, abriendo estas

${ }^{35}$ KUBLER, George: Arquitectura de los siglos XVII y XVIII, en Ars Hispaniae. Vol. XIV. Madrid, 1957.

${ }^{36}$ ELGAR, Frank: La pintura moderna, V, La pintura abstracta. Barcelona, 1966. En la citada biografía de RIVERO TARAVILLO, A.: Cirlot, ser y no ser..., op. cit., pp. 268269, el listado de traducciones ocupa dos páginas.

${ }^{37}$ CIRLOT, Juan Eduardo: Morfología y arte contemporáneo. Barcelona, 1955, p. 5.

38 Vid nota 20.

39 ARNHEIM, Rudolf: “QQué fue de la abstracción?”, en Ensayos para rescatar el arte. Madrid, 1992, p. 31 
palabras preliminares con la cita de Georg Büchner en Wozzeck: "Las líneas, las figuras, ¿quién puede leerlas?”. Y del filósofo Heráclito: "La Naturaleza gusta de ocultarse" $"$.

Del nítido carácter de su contenido nos puede dar una idea, cuando en el inicio del primer capítulo de la primera parte, al explicar la materia del libro, la primera figura nos ofrece el modo en que un dibujo de Kandinsky subraya en paralelo la transcripción visual de un tema de Beethoven, exponiéndonos a continuación en qué manera desde el post-impresionismo, el expresionismo, el surrealismo, el cubismo y la abstracción nos muestran todo un mundo de emulsiones, cristales, concreciones y formas vivientes de la naturaleza, con este rotundo juicio: "La afirmación de una identidad interna entre el mundo de lo anímico y el de lo físico tiene derivaciones importantísimas para la concepción del universo, la estética y el propio arte" ${ }^{41}$. En la segunda parte, trata no solo sobre la orgonomía de Wilhem Reich para quien la forma es movimiento congelado, sino también sobre la morfología general de Monod-Herzen, las leyes morfológicas de la Psicología, la Geomorfología, la Cristalografía y la Biología. La tercera parte está dedicada a la pura morfología a partir de las interpretaciones místico-matemáticas de Matila Ghyka hasta profundizar en la Psicología de la forma, sus leyes y propiedades a través de las obras de Wertheimer, Köhler, Lewin y Katz, en un momento en que Rudolf Arnheim no había popularizado aun las teorías de la Gestalt con sus famosos tratados, introduciéndonos a continuación en la producción psicológica de los símbolos y en la estética de sus formas para concluir en una síntesis general de la composición y sistematización, que conduciría a una auténtica teoría de la organización pues en todas las categorías existenciales se puede encontrar una forma (estructura exterior perceptible) y una estructura (forma u orden interno) ${ }^{42}$.

Su segunda gran obra como historiador del arte será el Diccionario de símbolos, "su libro preferido" como afirma en el prólogo de su segunda edición ${ }^{43}$. La primera edición había aparecido en 1958 con el título de Diccionario de símbolos tradicionales, dedicada también como esta segunda al doctor Marius Schneider ${ }^{44}$, etnólogo, filólogo, musicólogo e historiador de la música alemán a quien el centro Superior de Investigaciones Científicas de Barcelona había publicado un estudio sobre El origen musical de los animales-símbolos ${ }^{45}$. La segunda edición de este

${ }^{40}$ CIRLOT, J. E., Morfología y arte contemporáneo, op. cit., pp. 9 y 11.

${ }^{41}$ Ibidem, pp. 15, 16 y ss.

${ }^{42}$ Ibid., pp. 39-91.

${ }^{43}$ CIRLOT, Juan Eduardo: Diccionario de símbolos. Barcelona, 1969, p. 10. Cf. CIRLOT, Victoria: "Epílogo: las ediciones del Diccionario de símbolos". $3^{\mathrm{a}}$ ed., Madrid, 1998. Vid supra nota 32.

${ }^{44}$ CIRLOT, Juan Eduardo: Diccionario de símbolos tradicionales. Barcelona, 1958.

${ }^{45}$ RIVERO TARAVILlO, A.: Cirlot, ser y no ser..., op. cit., p. 93. 
famoso diccionario (Figura 2), dotada de espléndidas ilustraciones en cada página, supuso una fuente de inspiración a quienes entonces nos estrenábamos en el estudio del simbolismo ${ }^{46}$ y un eficaz acicate a los adalides de esta nueva tendencia en la historia del arte ${ }^{47}$, pues como afirmaba su autor al final de la introducción: "Queremos agregar solamente que consideramos nuestra obra más como un libro de lectura que de consulta"48. Ciertamente, se trataba de un libro de consulta pero también se podían leer de corrido sus densos e interesantes artículos desde la A a la Z.

En realidad, la introducción se convierte en un breve tratado sobre el tema, comenzando el primer capítulo con la delimitación de lo simbólico y su historicidad, para continuar en segundo lugar con el origen, desarrollo y continuidad de los símbolos tanto en Oriente como en Occidente, especificando el simbolismo onírico así como el alquímico. El tercer capítulo se ocupa de las distintas nociones del símbolo, abundando en el "ritmo común” de Schneider que explica la existencia de la analogía entre dos planos de la realidad para aproximarnos, finalmente, al mundo de los arquetipos, según Jung. En el cuarto capítulo se analiza la esencia del símbolo, su analogía y sus relaciones con la alegoría. El quinto capítulo se dedica al problema de la comprensión e interpretación de los símbolos en sus aspectos psicológicos y planos de significación, acercándonos a la sintaxis simbólica dentro del simbolizante y simbolizado. Para Cirlot el simbolismo es una ciencia exacta y utiliza para su investigación un sistema "comparado" por medio del estudio de la antropología, la mitología, la historia de las religiones, el esoterismo, la emblemática y el psicoanálisis, preocupándole más bien la identificación cultural del símbolo y su comprensión que su interpretación en una situación determinada ${ }^{49}$.

En tercer lugar, destaca su obra El espíritu abstracto, publicada en 1963, y que treinta años después alcanza su cuarta edición dedicada a Georges Mathieu (Figura 3$)^{50}$. Tras la siguiente cita de Elie Faure en El espíritu de las formas: "Una solidaridad universal une todos los gestos e imágenes de los hombres, no solo en el espacio, sino también y sobre todo en el tiempo", un breve prólogo nos explica el origen del libro en la lectura del libro de Herbert Kühn, Die Kunst Alt-Europas ${ }^{51}$, que trata del arte europeo desde la Prehistoria hasta el Medievo y que lo mueve a considerar el concepto de lo abstracto en todas sus manifestaciones desde el

${ }^{46}$ CÓMEZ RAMOS, Rafael: "La estrella de Salomón en la iglesia de San Isidoro de Sevilla”, Archivo Hispalense, 177, 1975, pp. 81-85, recogido después en CÓMEZ RAMOS, Rafael: Imagen y símbolo en la Edad Media andaluza. Sevilla, 1990, pp. 49-56.

${ }^{47}$ SEBASTIÁN, Santiago: Espacio y símbolo. Córdoba, 1977, p. 21, nota 3.

${ }^{48}$ CIRLOT, J. E.: Diccionario de símbolos, op. cit., p. 56.

49 Ibidem, pp. 15-56 y 9-10.

50 Vid nota 29.

${ }^{51}$ CIRLOT, Juan Eduardo: El espíritu abstracto. 4ª ed., Barcelona, 1993, pp. 5-16. 
Paleolítico Superior hasta la Edad del Bronce, las culturas clásicas, ibéricas y celtas para llegar al espíritu de la Alta Edad Media a través del arte vikingo, irlandés, islámico, bizantino y prerrománico hasta culminar en la síntesis del románico y el dinamismo del gótico, tratando en un capítulo final algunos aspectos del arte judío. Resultan particularmente curiosas las comparaciones de la decoración de hilo de vidrio de un vaso del Museo Romano Germánico de Colonia con una pintura de Georges Mathieu o también el diseño de un manto bizantino del siglo IX con la composición en blanco y negro de Theo van Doesburg (1918) del Kunstmuseum de Basilea ${ }^{52}$.

La cuarta obra que nos puede servir como ejemplo de su actividad historiadora del arte es Pintura gótica europea, publicada en 1969 (Figura 4) y que dedica "Para José Gudiol con amistad y reconocimiento", con quien mantenía una cordial relación desde 1953, visitando exposiciones y tiendas de anticuarios con objeto de ampliar su colección numismática ${ }^{53}$. Comienza con un prefacio como breve introducción histórica, justificando esta "obra de divulgación" en la que ha trabajado asistemáticamente varios años por mor de lo que podría denominarse "llamamiento de lo gótico" y que concluye con una cita de Paul Gauguin, que bien pudiera suscribir un pintor gótico: "No pintéis demasiado del natural. El arte es una abstracción, extraedla de la naturaleza soñando ante ella y pensad más en la creación que resultará... Es el único medio de ascender hacia Dios, haciendo lo que nuestro Divino Maestro: crear" ${ }^{4}$.

En la introducción se ocupa de la historia interna del espíritu gótico a partir de la famosa obra de Worringer hasta llegar a la Arquitectura gótica y escolástica de Erwin Panofsky, dentro del contexto histórico y cultural de la época para tratar después sobre la evolución del estilo de la pintura gótica en sus distintas fases $^{55}$. Los once capítulos siguientes están dedicados al estudio pormenorizado de cada una de las distintas escuelas europeas, terminando con un colofón sobre el fin de la Edad Media en el que piensa que en un mundo tan distinto a aquél, tal vez, aún podamos entrar en contacto con aquellos ideales y recuperar nuestra alma. La obra va acompañada de un útil ensayo de cronología como apéndice y abundantes ilustraciones en blanco y negro con xilografías de la Legenda aurea, el Ars moriendi e incluso algunas marcas notariales del siglo XIV.

Para Cirlot, el artista en unidad con el todo, después de haber pactado con lo real, explica el mundo que le rodea y se impone gracias a su mágico poder transformador de la realidad, modificándola en cierta manera pues, como el mismo afirma: "A la inversa de lo que pretendía Taine, el artista explica su coyuntura

${ }^{52}$ Ibidem, pp. 80-81 y 124-125.

${ }^{53}$ CIRLOT, Juan Eduardo: Pintura gótica europea. Barcelona, 1969, p. 5; y RIVERO

TARAVILLO, A.: Cirlot, ser y no ser..., op. cit., p. 108.

${ }^{54}$ CIRLOT, J. E.: Pintura gótica europea, op. cit., pp. 7 y 10.

${ }^{55}$ Ibidem, pp. 13-32. 
histórica y ambiental, pero no sucede, sino en una medida muy restringida, lo contrario. Por definición, el artista es el que tiene poder para imponerse a lo dado y modificarlo en cierto sentido. No solo la naturaleza imita al arte. También la sociedad y la historia acaban por imitarlo" 56 .

Finalmente, la obra que concluirá su labor como historiador del arte, un año antes de su muerte, será Arte del siglo $X X$, un libro en dos volúmenes, el primero dedicado a la arquitectura y la escultura y el segundo a la pintura ${ }^{57}$, que significó mucho para quienes entonces preparábamos los exámenes de Arte contemporáneo en el último año de nuestra carrera. En la introducción histórica se plantea la pregunta acerca de qué caracteriza la Weltanschaung del siglo XX, con la siguiente respuesta: “¿En qué se distingue esta época? Ante todo, se diferencia por dos aceleraciones de rapidísimo ritmo: el demográfico y el técnico"58. Tras citar a Foucault, D'Ors, Teilhard de Chardin, Romano Guardini y Pablo VI, nos habla de Mircea Eliade cuando menciona a los artistas como sismógrafos que señalan puntualmente los cambios de la historia, que significan más mutaciones que evolución en el siglo $\mathrm{XX}^{59}$. En el colofón final, tras considerar que a la ola actual de desenfreno seguiría probablemente un arte espiritualista, recuerda a André Breton cuando preconiza el arte del futuro obediente a "un modelo puramente interior", y concluye con esta afirmación: "Los graves problemas con que va a enfrentarse la humanidad en los próximos treinta años, por no superar el umbral del 2000, exigirán esa condición espiritual” ${ }^{\circ}$.

Fecha de recepción: 20 de diciembre de 2016

Fecha de aceptación: 20 de enero de 2017

${ }^{56}$ Apud RIVERO TARAVILlO, A.: Cirlot, ser y no ser..., op. cit., p. 281.

${ }^{57}$ CIRLOT, Juan Eduardo: Arte del siglo XX. 2 vols., Barcelona, 1972.

${ }_{58}$ Ibidem, vol. I, p. 1.

${ }^{59}$ Ibid., pp. 2-3.

${ }^{60}$ Ibid., vol. II, p. 408. 


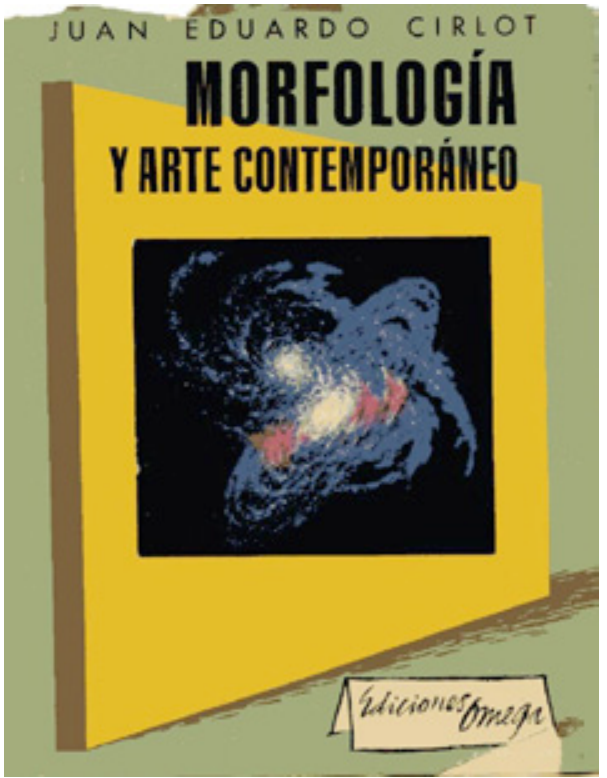

Figura 1. Cubierta de Morfología y arte contemporáneo (1955).

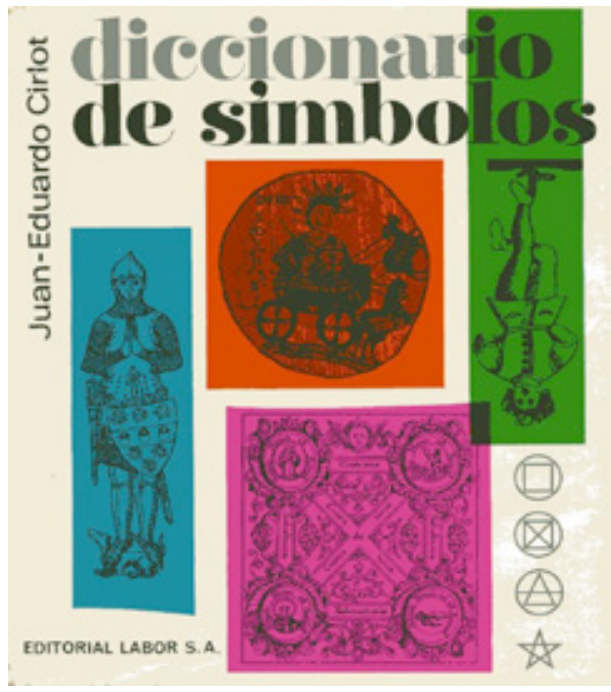

Figura 2. Cubierta de Diccionario de símbolos, $2^{\mathrm{a}}$ edición (1968).

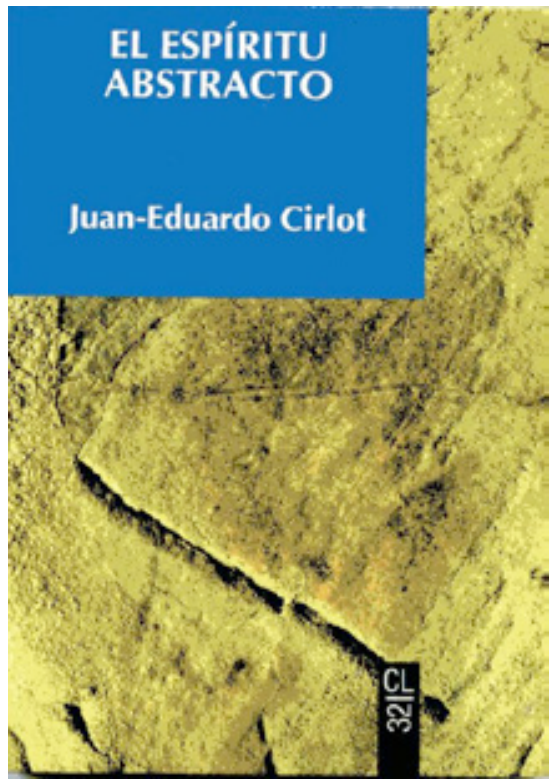

Figura 3. Cubierta de El espíritu abstracto, $4^{\text {a }}$ edición (1993).

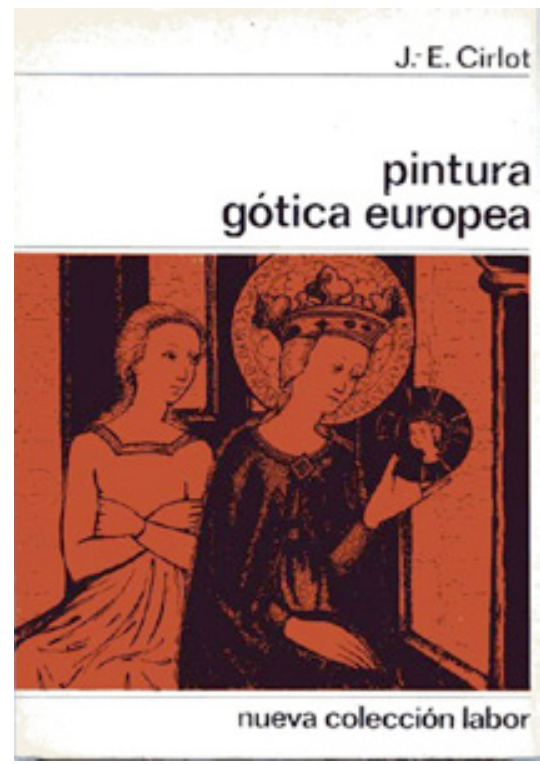

Figura 4. Cubierta de Pintura gótica europea (1969). 